\title{
Total Hip Arthroplasty in Acetabular Deficiency: Experience in Al Razi Hospital, Kuwait
}

\author{
Wieslaw Pospula Tarek Abu Noor \\ Department of Orthopedics, Al Razi Hospital, Kuwait
}

Key Words

Acetabular deficiency $\cdot$ Total hip replacement

\begin{abstract}
Objective: To report clinical and radiological outcomes of cemented and cementless total hip arthroplasty for primary and secondary osteoarthritis with a deficiency of acetabular bone stock. Subject and Methods: Thirty-seven patients (16 male and 21 female) having 41 hips affected by primary and secondary acetabular bone stock defect that were operated using cemented $(n=25)$ and cementless $(n=16)$ hip replacement were followed for an average period of 37 (range 12100) months. Bone defect was classified according to American Academy of Orthopedic Surgery criteria. Different types of bone graft techniques and metal reinforcements were used. Merle d'Aubigné clinical score was used to calculate clinical outcomes. Geometrical position of the acetabular component, cup integration, hip center and graft integration were assessed. Results: The mean clinical score improved significantly from 10.6 patients preoperatively to 16.7 patients postoperatively; $95 \%$ of the cups were in the desired position and were considered integrated and the bone graft remodeled in most cases. There were 2 deep infections, 1 dislocation and 2 cases of transient neurological deficit. No significant differences in final clinical and radiological outcomes, rate of loosening and rate of complications were found between cemented and cementless acetabular replacements. Conclusion: The results show that
\end{abstract}

\section{KARGER}

Fax +4161306 1234

E-Mail karger@karger.ch

www.karger.com
(C) 2007 S. Karger AG, Basel

1011-7571/07/0165-0373\$23.50/0

Accessible online at:

www.karger.com/mpp reconstruction of acetabular bone deficiency can be accomplished with few complications using either a cemented or cementless acetabular component with or without grafting according to the clinical situation.

Copyright $\odot 2007$ S. Karger AG, Basel

\section{Introduction}

Acetabular deficiency is a complex and difficult clinical problem, the sequela of nontraumatic pathology such as developmental dysplasia of the hip (DDH), spondyloepiphyseal dysplasia and protrusio acetabuli. It also occurs in posttraumatic degenerative joint disease, secondary to acetabular trauma, and in loosening of the acetabular component of total hip replacement [1-3]. Previous surgical procedures may contribute to a defect of acetabular bone stock [4]. In most cases, secondary osteoarthritis develops, requiring total hip replacement.

Several classifications of acetabular defects have been used including those of Paprosky et al. [5], the American Academy of Orthopedic Surgery (AAOS) [6], and the Endoklinik classification [5]. Treatment depends on several factors, including the general and local condition, for which the extent of the defect seems to be most important. During surgery, sufficient bone stock should be restored in order to place the prosthetic cup well supported in the anatomical position, or the existing bone stock should be utilized and the acetabular component fixed in

Wieslaw Pospula, MD, PhD

Al Razi Orthopedic Hospital

PO Box 4235

13043 Safat (Kuwait)

Tel. +965 917 4515, Fax +965 482 2240, E-Mail pospulawieslaw@hotmail.com 
a nonphysiological position $[7,8]$. Structural bone grafting using massive allografts and impacted grafting using morcelized autogenous and allogenous bone are gradually being superseded by a cementless megacup made of titanium or tantalum with osteoinductive capacity $[9,10]$. We report our experience of total hip replacement for primary or secondary osteoarthritis with deficient acetabulum in Al Razi Hospital, Kuwait.

\section{Material and Methods}

Among 210 patients operated for total hip arthroplasty for various pathologies during the period 1994-2006, there were 41 cases of primary and secondary acetabular deficiency, 16 male (16 hips) and 21 female (25 hips) with an average age of 43 years, ranging from 21 to 84 years with 4 cases of bilateral hip replacement. The average follow-up was 37 months, ranging from 12 to 100 months. The right hip was affected in 24 cases, the left in 17 cases. There was posttraumatic acetabular defect due to acetabular fracture in 14 cases; in 16, nontraumatic pathology was present, and in 11 cases the acetabular bone stock was deficient because of loosening of the previously implanted acetabular component. The defect was classified according to the AAOS classification system [6]. Defect type Ia was found in 6 cases, Ib in 5, type II in 16 and type III in 14 cases. There was no case of defect type IV. The hip was approached posteriorly in 14 cases and transgluteally in the remaining 27. In 16 cases the surgical technique included cementless acetabular replacement and cemented acetabular replacement in 25. A Bicon threaded shell (Plus Orthopedics, Rotkreuz, Switzerland) was used in 15 cases for cementless replacement, and EPF Press-Fit shell (Plus Orthopedics) was used in 1 case. For cementless implants, a Plus Endoprothetik (Rotkreuz, Switzerland) polyethylene insert was used in 14 and ceramic inserts in 2 cases. In cementless hip replacement, a 28 -mm diameter metal head and a ceramic head were used in 4 and 12 cases, respectively. In cemented implants, all femoral heads were Orthinox Stainless Steel 28 diameter heads (Stryker-Howmedica, UK). Similarly, there were 25 cemented and 16 cementless femoral components. All 25 cemented femoral stainless steel stems were produced by Stryker-Howmedica, UK, and all 16 cementless titanium doubletaper SL stems were products of Plus Endoprothetik, Rotkreuz, Switzerland. The clinical outcome was assessed according to the Merle d'Aubigné hip score [11]. Radiological assessment involved geometrical position of the cup, hip center, and signs of integration of the cup and bone graft. In cases of cemented cup integration, assessment was based on the absence of radiolucent or radiodense lines in the cement/bone and implant/cement interfaces. The cementless titanium shell was considered integrated when no gaps and lucencies were present in the bone/implant interface. Graft integration was assessed according to the presence or absence of a distinctive line between the graft and host bone.

Comparison of clinical and radiological outcomes and statistic significance was analyzed using SPSS package for Windows version 11.5. The numerical data were analyzed using pairedsamples $t$ test if all patients were analyzed; independent-sample $t$ test for equality of means was used when two groups (i.e. cemented vs. cementless) were studied. Categorical data were analyzed using chi-square test.
Table 1. Comparison of preoperative and final clinical parameters measured according to Merle d'Aubigne score in cemented and cementless replacement

\begin{tabular}{lll}
\hline Clinical parameter & \multicolumn{2}{c}{ Clinical score } \\
\cline { 2 - 3 } & cemented cup & cementless cup \\
\hline Pain preoperatively & 3.2 & $3.8^{*}$ \\
Pain final & 5.6 & 5.8 \\
ROM preoperatively & 3.5 & $3.8^{*}$ \\
ROM final & 5.4 & 5.9 \\
Walking preoperatively & 3.2 & $3.8^{*}$ \\
Walking final & 5.3 & 5.4 \\
Total score preoperatively & 10.1 & $11.5^{*}$ \\
Total score final & 16.3 & 17.2 \\
\hline
\end{tabular}

ROM $=$ Range of movement

${ }^{*} \mathrm{p}<0.01$.

\section{Results}

Clinical results, rated in Merle d'Aubigné score, improved in all aspects of assessed parameters: pain, range of movement, and walking capacity (table 1). The average scores of pain, range of movement, and walking capacity for the entire population of patients before surgery were 3.4, 3.6 and 3.5, respectively, while the corresponding scores for the same group at the last follow-up were 5.7, 5.6 and 5.3, respectively. Hence, the total preoperative scores were 10.6 and 11.5, respectively, and the improvement in clinical outcome was statistically significant $(\mathrm{p}<$ 0.01 ), using paired samples ( $t$ test). Comparison of initial clinical results between the cemented and cementless groups using independent sample $t$ test for equality of means similarly revealed significant differences $(\mathrm{p}<$ 0.01 ). Final clinical results did not reveal significant differences between the two groups (table 1).

The radiological results showed that 39 (95\%) acetabular cups were implanted at an optimal inclination (30$50^{\circ}$ ). Anteversion was not assessed in this group, as a reliable method of assessment was not available, which concerns the cementless titanium shell in particular. In 2 (5\%) cases, the cup was intentionally implanted in a horizontal position; there was no case of a vertical position of the acetabular component. The acetabular component was implanted at the anatomical level in 39 cases (95\%). In 2 cases, the cup was implanted intentionally in a high hip center position in order to impact the cementless shell in healthy host bone. The vertical displacement did not exceed $3.5 \mathrm{~cm}$. The acetabular component was considered 

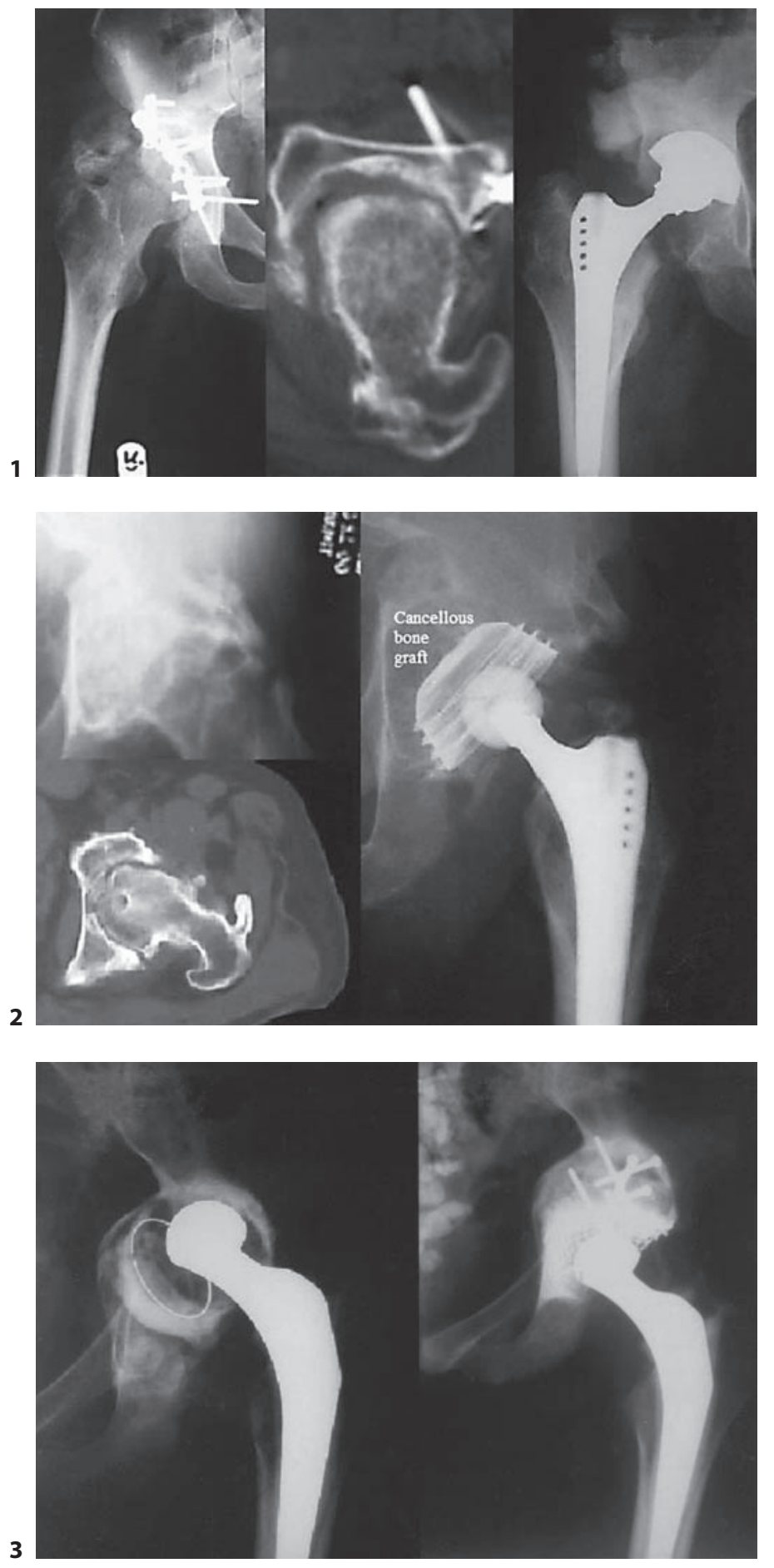

integrated in 39 cases (95\%). All cementless cups were integrated; one cemented cup had lucency in two zones and one cup was loose. In 9 cases, no graft was used, in 30 the graft was integrated and in 2, graft resorption was found (fig. 1-5). Complications included 1 dislocation
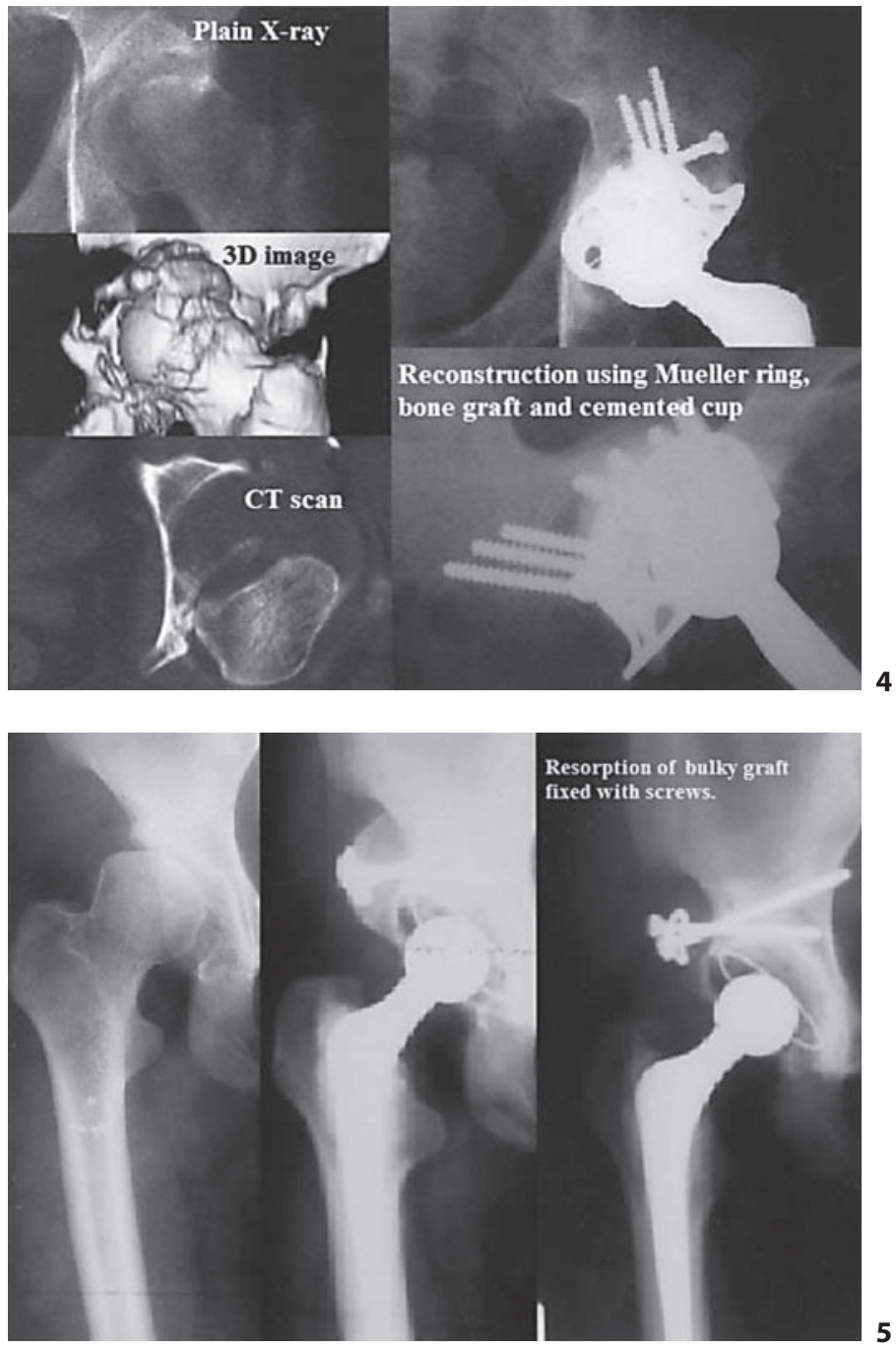

Fig. 1. Combined defect treated by cementless press-fit cup without bone graft. High hip center.

Fig. 2. A case of cavitary posttraumatic defect treated by cementless hip replacement with threaded Bicon cup. Defect filled with cancellous graft and compressed with the cementless shell.

Fig. 3. Combined defect treated by impaction grafting, metal reinforcement mesh and cemented cup.

Fig. 4. Combined defect of acetabular bone treated by bone graft, reinforcement Mueller ring and cemented cup.

Fig. 5. Resorption of the bulky femoral head graft fixed with screws.

that was treated conservatively, 2 cases of deep infection, 1 case of deep vein thrombosis, and 2 cases of transient femoral nerve palsy, which resolved within 6 weeks. The initial clinical score of patients treated with a cemented cup was significantly inferior compared with the same 
score of patients treated with cementless revision (table 1). Comparison of radiological outcomes, loosening rate and complications between cemented and cementless acetabular reconstruction using chi-square test did not reveal significant differences in all aspects.

\section{Discussion}

Acetabular deficiency affects primary and revision hip arthroplasty. Classification of acetabular bone defect is the subject of debate. Intraobserver and interobserver reliability is poor according to a number of studies $[6$, 12]. The AAOS classification was used for both primary and secondary defects because it is relatively simple and adaptable to our material consisting of various types of bone defect. The cases were classified as moderate in severity, as nearly $70 \%$ were segmental and cavitary and about $30 \%$ were combined, mostly posttraumatic cases. The decision to use a particular method of treatment was taken preoperatively according to age of the patient, type of pathology and available radiographic documentation. In all cases, the plain X-ray was used to assess the preoperative situation and if possible CT scan was used to get additional information. Not all patients could afford financing of CT scanning. In contained cavitary and segmental central defects, we tended to use the threaded cementless Bicon shell to compress a cancellous graft, filling the defect (fig. 2) [13]. This was not possible using the press-fit cup. For combined defects, there were three options: the defect could be managed by bulky graft augmented with screws alone (fig. 5) or a reinforcement ring (fig. 4) [14] or cancellous impacted grafts with metal mesh and screws followed by a cemented polyethylene cup (fig. 3). Another reported technique is fixation of the cementless threaded, press-fit titanium shell or custommade implant in available bone stock in order to avoid bone graft $[15,16]$. In such a case, the hip center may not be in the anatomical site (high hip center). This technique is acceptable, especially in young patients with good bone quality as shown in figure 4 . A higher position of the hip center did not adversely affect the result provided it was not lateralized $[17,18]$. Postoperative clinical score assessed on average at 37 months postoperatively did not differ, because both groups had good to excellent results (16.3 and 17.2 patients, respectively). A similar observation was reported by Clohisy and Harris [19]. The clinical results did not differ significantly between patients with no trauma and posttrauma and the previous surgical procedure group. In nearly all cases where a bone graft was used, we observed remodeling of the graft. As fresh frozen bone grafts are not available in our hospital, we used a combination of commercially available bone substitute with autogenous bone graft. In 2 cases, the graft was not incorporated. In the first case, the bulky graft was used to augment the superolateral aspect of the acetabulum. Gradual disappearance of the graft was observed (fig. 5). Obviously, the graft was not loaded, which is the reason for this phenomenon. In the second case, there was chronic low-grade infection preventing the incorporation of the graft. In 1 case of deep infection and debridement, prolonged antibiotic treatment was successful. In the second case with previous multiple operations, the infection could not be controlled. This patient necessitated having a long stem femoral implant that was not available and was referred to another center. Soft tissue laxity was the reason for 1 case of dislocation. Closed reduction and bed rest for 3 weeks in hip spica plaster cast was sufficient to stabilize the hip. This treatment strategy is recommended in other reports of using the same implant [13]. Two cases of transient palsy of the femoral nerve occurred in patients with osteoarthritis secondary to DDH with a previous history of multiple operations on the affected hip. Adhesions and a lack of elasticity of the soft tissues may be partially responsible in addition to forceful retraction. Both cases recovered within 3-6 weeks postoperatively. A similar complication has been reported by other authors in cases of DDH $[2,13]$.

\section{Conclusion}

During the average follow-up period of 37 months, cemented and cementless reconstruction of acetabular bone defect with different types of reinforcement and bone graft resulted in good clinical and radiological outcome. There were no statistically significant differences with respect to final clinical outcome, rate of loosening and rate of complications between cemented and cementless implants. Because of the short follow-up, these results must be validated by a further prospective follow-up. 


\section{References}

$>1$ Cucker JM: Management strategies for acetabular defects in revision total hip arthroplasty. J Arthroplasty 2002;4(suppl 1):153156.

$>2$ Hartofilakidis G, Karachalios T: Total hip arthroplasty for congenital hip disease. J Bone Joint Surg Am 2004;86A:242-250.

3 Weber M, Berry DJ, Harmsen WS: Total hip arthroplasty after operative treatment of an acetabular fracture. J Bone Joint Surg Am 1998;80:1295-1305.

4 Murphy S: Management of acetabular bone stock deficiency. J Arthroplasty 2005;4(suppl 2):85-90.

$\checkmark 5$ Paprosky WG, Perona PG, Lawrence JM: Acetabular defect classification and surgical reconstruction in revision arthroplasty. J Arthroplasty 1994;9:33-44.

$\checkmark 6$ Gozzard C, Blom A, Smith E, Learmonth I: A comparison of the reliability and validity of bone stock loss classification systems used for revision hip surgery. J Arthroplasty 2003; 18:638-642.

7 Boldt JG, Dilawari P, Agarwal S, Drabu KJ: Revision total hip arthroplasty using impaction bone grafting with cemented nonpolished stems and charnley cups. J Arthroplasty 2001;16:943-952.
8 Dearborn JT, Harris WH: High placement of an acetabular component inserted without cement in a revision total hip arthroplasty after a mean of ten years. J Bone Joint Surg Am 1999;81:469-480.

9 Chen WM, Engh CA Jr, Hopper RH Jr, McAuley JP, Engh CA: Acetabular revision with use of a bilobed component inserted without cement in patients who have acetabular stock deficiency. J Bone Joint Surg Am 2000;82:197-206.

10 Unger AS, Levis RJ, Gruen T: Evaluation of porous tantalum uncemented acetabular cup in revision total hip arthroplasty: clinical and radiological results of 60 hips. J Arthroplasty 2005;20:1002-1009.

11 d'Aubigné MR, Postel M: Functional results of hip arthroplasty with acrylic prosthesis. J Bone Joint Surg Am 1954;76:129-138.

12 Campbell DG, Garbuz DS, Masri BA, Duncan C: Reliability of acetabular bone defect classification systems in revision total hip arthroplasty. J Arthroplasty 2001;16:83-86.

13 Schlegel UJ, Bitsch RG, Pritsch M, Clauss M, Mau H, Breusch S: Mueller reinforcement rings in acetabular revision: outcome in 164 hips followed for 2-17 years. Acta Orthop 2006;77:234-241.
14 Grubl A, Chiari C, Gruber M, Kaider A, Gottsauner-Wolf F: Cementless total hip arthroplasty with a tapered, rectangular titanium stem and a threaded cup. J Bone Joint Surg Am 2002;84A:425-431.

15 Bellabarba C, Berger RA, Bentley CD, Quigley MS, Jacobs JJ, Rosenberg AG, Sheinkop $\mathrm{MB}$, Galante J: Cementless acetabular reconstruction after acetabular fracture. J Bone J Surg Am 2001;83A:868-876.

16 Joshi AB, Lee J, Christensen C: Results for custom acetabular component for acetabular deficiency. J Arthroplasty 2002;17:643-648.

${ }_{17}$ Bozic K, Freiberg A, Harris W: The high hip center. Clin Orthop Relat Res 2004;420:101105.

18 Morag G, Zalzal P, Liberman B, Safir O, Flint M, Gross AE: Outcome of revision hip arthroplasty in patients with previous total hip replacement for developmental dysplasia of the hip. J Bone Joint Surg Br 2005;87:10681072.

19 Clohisy JC, Harris WH: Matched-pair analysis of cemented and cementless acetabular reconstruction in primary total hip arthroplasty. J Arthroplasty 2001;16:697-705. 